\title{
Higiene Y BAÑOS EN CÓRDOBA A FINALES DE LA EdAd MEdia a TRAVÉS DE LA DOCUMENTACIÓN NOTARIAL ${ }^{1}$
}

\author{
Margarita Cabrera Sánchez ${ }^{2}$ \\ Universidad de Córdoba
}

\begin{abstract}
Resumen
El objetivo del presente trabajo es conocer la historia de algunos de los baños que existieron en Córdoba a finales del Medievo, utilizando, sobre todo, la documentación notarial de la segunda mitad del siglo XV. Gracias a los testimonios notariales hemos llegado a obtener una gran cantidad de datos -en su inmensa mayoría inéditos- sobre esos recintos, hasta el punto de que conocemos su ubicación, la identidad de sus propietarios -en todos los casos fueron miembros de la nobleza-, cuál pudo ser su funcionamiento y fisonomía e incluso algunas de las normas de uso de las instalaciones. Además, todas esas noticias extraídas de la documentación notarial se han podido completar, en ocasiones, con la información obtenida a través de las intervenciones arqueológicas, que han permitido sacar a la luz restos de algunos de esos recintos.
\end{abstract}

\section{Palabras clave}

Higiene; baños; medicina; nobleza; Córdoba.

\begin{abstract}
The purpose of this paper is to know the history of some baths in Cordoba at the end of Middle Ages taking above all into account the notarial documents of the second half of the 15 th century. Thanks to the notarial evidences we have obtained a large information - unpublished a great number of themabout such sites: their locations, the names of their owners, belonging in all cases to nobility, their feasible functioning and physiognomy as well as some rules to be kept by the user. In addition to these informations, we were occasionally able to complete them with the aid of archaeological diggings which bring out rests of some such baths.
\end{abstract}

\section{Keywords}

Hygiene; baths; medicine; nobleness; Cordoba.

\section{Résumé}

Dans ce travail, nous avons voulu étudier et connaître l'histoire de certains bains publics qui ont existé à Cordoue, à la fin du Moyen Âge. Dans ce but, nous avons principalement utilisé des documents notariaux de la deuxième moitié du XVème siècle. Grâce à ces derniers, nous avons pu réunir une grande quantité de données - pour la plupart inédites- sur ces enceintes: nous connaissons à présent

1 Este trabajo forma parte del proyecto de investigación titulado El conocimiento científico y técnico en la Península Ibérica (siglos XIII-XVI): producción, difusión y aplicaciones (HAR2012-37357), subvencionado por el Ministerio de Economía y Competitividad.

2 Correo electrónico: ca1casam@uco.es. 
leur emplacement, l'identité de leurs propriétaires qui appartenaient tous à la noblesse, leur fonctionnement et apparence et même certaines normes d'utilisation des installations. Ajoutons que tous ces renseignements d'origine notariale ont pu être complétés par les recherches archéologiques qui ont permis de découvrir les restes de quelques-unes de ces enceintes.

\section{Mots-clés}

Hygiène; bains; médecine; noblesse; Cordoue.

\section{Introducción}

Entre los numerosos vestigios del pasado que se pueden encontrar en Córdoba, resultan poco conocidas, en general, las instalaciones de baños que frecuentaron aquellos hombres y mujeres que habitaron en esa ciudad durante el Medievo. Y todo ello a pesar de que esos recintos dedicados a la higiene, que tan habituales fueron entre la sociedad andalusí, debieron de proliferar de forma especial en la propia capital de al-Ándalus, aunque las fuentes impidan comprobar realmente la importancia cuantitativa de los mismos. De igual modo, desconocemos el número de baños existentes tras la conquista cristiana, dado que no se han conservado los libros de repartimiento. Precisamente utilizando este tipo de fuentes, hace algo más de una década, C. Camps y J. Torró, pudieron constatar que, en Valencia, existían unos 25 baños cuanto tuvo lugar la conquista de la ciudad. Al parecer, fueron escasos los baños árabes que perduraron en los años siguientes, a pesar de lo cual, a mediados del siglo XIV, se documentan aproximadamente 15 establecimientos de baños, lo que evidencia que, a pesar de que la mayor parte de los hammāms ya no estaban en uso, "la oferta balnearia" seguía siendo importante. ${ }^{3}$

En el caso de Córdoba, como ya se ha indicado, la inexistencia de fuentes adecuadas no nos permite saber qué es lo que sucedió, a partir del siglo XIII, con la red de baños que la ciudad heredó de los musulmanes. ${ }^{4}$ En realidad, no contamos con un estudio de conjunto sobre los baños medievales cordobeses, ya que el trabajo de M. Muñoz, realizado hace más de cincuenta años, es un repertorio sobre los baños árabes que existieron en Córdoba según el citado autor, pero en el que la información, al menos en determinados aspectos, no aparece debidamente contrastada; ${ }^{5}$ y el resto de trabajos sobre el tema son estudios parciales referidos a la época musulmana y centrados, exclusivamente, en el análisis arqueológico. ${ }^{6}$ Sin embargo, afortunadamente, las fuentes notariales de la segunda mitad del siglo XV proporcionan numerosas noticias sobre

\footnotetext{
3 Concepción CAmps García y Josep Torró I ABAD, "Baños, hornos y pueblas. La pobla de Vila-rasa y la reordenación urbana de Valencia en el siglo XIV", Historia de la ciudad II. Territorio, sociedad y patrimonio. Una visión arquitectónica de la historia de la ciudad de Valencia, ed. Icaro, Valencia, 2002, p. 127.

4 En el caso de los baños de Sevilla, por ejemplo, hace ya veinte años, las fuentes disponibles permitieron a M. Valor reconstruir la historia de esos recintos (Magdalena Valor Piechotta, "Los baños en la Sevilla islámica", Arqueología Medieval, 3 (1995), pp. 161-169).

5 Miguel Muñoz VÁzquez, "Los baños árabes de Córdoba", Al-Mulk, 2 (1961-1962), pp. 53-117.

6 Se puede ver una actualización bibliográfica reciente de esos trabajos en Rafael Clapés SALMORAL, "Un baño privado en el arrabal occidental de Madinat Qurtuba", Arqueología y Territorio Medieval, 20 (2013), pp. 114-117.
} 
algunos baños que existían en ese momento en el recinto urbano y que, en determinados casos, eran de origen árabe, como tendremos ocasión de comprobar más adelante. En ocasiones, ciertos testimonios facilitan una gran cantidad de datos -en su inmensa mayoría inéditos- sobre esos recintos, hasta el punto de permitirnos conocer su ubicación, la identidad de sus propietarios, cuál pudo ser su funcionamiento y fisonomía e incluso algunas de las normas de uso de las instalaciones. Además, todas esas noticias extraídas de la documentación notarial se pueden completar, en ocasiones, con la información obtenida a través de las intervenciones arqueológicas, que han permitido sacar a la luz restos de algunos de esos recintos. Utilizando como base las fuentes notariales, nos ha parecido interesante realizar el presente trabajo, que tiene como finalidad reconstruir la historia -desconocida hasta ahora- de algunos de los baños -aquellos sobre los que han quedado testimonios notariales- que frecuentaron los cordobeses de finales del Medievo, tratando de acercarnos también a su vida cotidiana y, en especial, a sus hábitos higiénicos. ${ }^{7}$

Hace ya algunos años, en un interesante trabajo, R. Córdoba señalaba que, durante la época de dominio cristiano de la ciudad, la pervivencia en la utilización de los baños pone de manifiesto que los cristianos adoptaron algunos hábitos higiénicos de los andalusíes, ${ }^{8}$ aunque también hay que tener en cuenta que, dejando a un lado el caso particular de la antigua ciudad califal, la abundante presencia de instalaciones de baños públicos durante los últimos siglos del Medievo -realidad que se puede comprobar fácilmente en las numerosas representaciones de la época que han llegado a nosotros- $-{ }^{9}$ seguramente tuvo mucho que ver también con el carácter social que tenían este tipo de recintos, ${ }^{10}$ al margen de que, como es obvio, se tratase de lugares en los que se atendía a la higiene corporal y a los que, por tanto, se podía acudir para mantener la limpieza del cuerpo, dado que, tal y como se puede observar en los textos médicos medievales, la práctica del baño era beneficiosa para la salud.

De hecho, en los regimina sanitatis que vieron la luz durante los siglos XIII y XIV, es fácil encontrar capítulos dedicados al baño. Es lo que hemos podido comprobar al

\footnotetext{
Sobre los baños medievales, y en particular sobre los de Valladolid, resulta especialmente detallado y documentado el libro de Magdalena Santo Tomés Pérez, Los baños públicos en Valladolid. Agua, higiene y salud en el Valladolid medieval, ed. Ayuntamiento de Valladolid, Valladolid, 2002, en concreto, las pp. 43-86. Y, en el caso de Madrid, también aportan noticias al respecto Laura BURGUETE Ors y Jose Miguel Lorenzo ArRiBas, "Limpieza y contaminación en la villa de Madrid durante la Edad Media: casas de baño y tenerías", Agua y sistemas hidráulicos en la Edad Media hispana, Cristina Segura Graíño (edt.), ed. Asociación Cultural Al-Mudayna, Madrid, 2003, pp. 87-102.

8 Ricardo CóRdoba de la Llave, "Algunas consideraciones sobre el legado tecnológico andalusí en la Córdoba cristiana", Acta historica et archaeologica mediaevalia, 18 (1997), p. 374.

9 A modo de ejemplo, ver las escenas de baños que aparecen repartidas por todo el libro de Hans Peter DuerR, Nudité et pudeur. Le mythe du processus de civilisation, ed. Éditions de la Maison des sciences de l'homme, Paris, 1998.

10 Norman John Greville Pounds, La vida cotidiana: historia de la cultura material, ed. Crítica, Barcelona, 1992, pp. 255-256.
} 
consultar los tratados de Pedro Hispano, ${ }^{11}$ Aldobrandino de Siena ${ }^{12}$ o Juan de Toledo, ${ }^{13}$ realizados durante la primera de esas centurias, ${ }^{14}$ y el tratado de Arnau de Vilanova, ${ }^{15}$ que, al parecer, data de comienzos del siglo XIV. ${ }^{16}$ En algunas de esas obras -sucede así con el Liber de conservanda sanitate de Pedro Hispano- se hacía alusión, de forma detallada, a los beneficios que reportaba el baño. ${ }^{17}$ Por su parte, Arnau de Vilanova relacionaba el hábito del baño con el ejercicio físico, insistiendo en el hecho de que aquél era beneficioso tanto para las personas que practicaban ejercicio como para aquellas que no lo hacían. ${ }^{18}$ Además, los autores de esos textos no se olvidan de mencionar distintos tipos de baños. Así, por ejemplo, Aldobrandino de Siena se refiere al que se llevaba a cabo "en estuves et en cuves"19 y Arnau de Vilanova alude a los baños "dela estuba" y "de agua". ${ }^{20}$ Por su parte, Bernardo de Gordonio, en su Tratado de el regimiento de las

11 María Helena da Rocha Pereira, Obras médicas de Pedro Hispano, ed. Universidad de Coimbra, Coimbra, 1973, pp. 482-483.

12 Aldobrandino DE SiEnA, Le régime du corps de maitre Aldebrandin de Sienne, ed. Louis Landouzy y Roger Pepin, Librairie ancienne Honoré Champion, Paris, 1911, pp. 25-27.

13 No hemos podido acceder a varias ediciones antiguas del tratado de Juan de Toledo (Arnaldi de Villanova Opera medica omnia, vol. 10. 1, ed. Luis García-Ballester y Michael Rogers McVaugh, Publicacions de la Universitat de Barcelona, Barcelona, 1996, pp. 517-518, nota 11) y tampoco a la edición más reciente de ese tratado, por tratarse, al parecer, de una memoria de licenciatura inédita (Gabriel MARTínEZ I FERRA, Aspectes de la medicina preventiva baixe-medieval: la traducció catalana del Liber de conservanda sanitate de Johannes de Toledo, 1997). Sin embargo, en la obra se incluye un capítulo referido al baño (Arnaldi de Villanova Opera medica omnia, vol. 10. 1, ed. cit., p. 518).

14 Sobre la cronología de Pedro Hispano y sobre las fechas de realización de los tratados de Aldobrandino de Siena y de Juan de Toledo, ver Arnaldi de Villanova Opera medica omnia, vol. 10. 1, ed. cit., p. 523, p. 520 y p. 517.

15 Arnau de Vilanova, El maravilloso regimiento y orden de vivir (una versión castellana del Regimen sanitatis ad regem aragonum), ed. Juan Antonio Paniagua Arellano, Cátedra de Historia de la Medicina, Zaragoza, 1980, fols. 4v.-5v.

16 Ibidem, p. 35.

17 Señalaba, textualmente, lo siguiente: "Note-se que os banhos em certo modo são uma coisa deliciosa, mas quanto bem fazem é também quanto inconveniente causam. Os seus benefícios são provocar o sono, limpar, desopilar, raspar, soltar, dirigir e atrair a nutrição à superfície da carne [...]" (María Helena DA Rocha Pereira, Obras médicas..., p. 482). A estos beneficios derivados de la práctica del baño habría que añadir el poder curativo del baño termal, al que se hace referencia en un trabajo publicado en los últimos años (Lluís Cifuentes i Comamala y Antònia Carré Pons, "Práctica social, saber médico y reflejo literario de la cultura del baño en el contexto catalán medieval", Anuario de Estudios Medievales, 39/1 (enero-junio de 2009), p. 209). Sobre las propiedades medicinales del baño, ver el estudio reciente de Janna Coomans y Guy Geltner, "On the street and in the bathhouse: medieval galenism in action?", Anuario de Estudios Medievales, 43/1 (enero-junio de 2013), pp. 65-67.

18 Arnau de Vilanova, El maravilloso regimiento y orden de vivir (una versión castellana del Regimen sanitatis ad regem aragonum), ed. cit., fol. 5r.

19 Aldobrandino DE SiENA, Le régime du corps de maitre Aldebrandin de Sienne, ed. cit., p. 26.

20 Arnau DE VIlanova, El maravilloso regimiento y orden de vivir (una versión castellana del Regimen sanitatis ad regem aragonum), ed. cit., fol. 5r. 
enfermedades agudas, realizado al parecer a finales del siglo XIII, ${ }^{21}$ hace una distinción entre el "que se haze en tina con agua caliente" 22 y el "estufado". ${ }^{23}$

Desconocemos hasta qué punto se seguían los consejos prescritos por los galenos en todo lo relacionado con la higiene, aunque es fácil imaginar que serían los miembros de los sectores sociales más acomodados los que, en mayor medida, ponían en práctica esas recomendaciones, no sólo porque podían acceder con mayor facilidad que el resto de la sociedad a esas obras médicas, sino porque, en su propio ámbito doméstico, la mayor disponibilidad de agua y la existencia de sirvientes encargados de preparar el baño debían de facilitar de forma especial el aseo corporal. Y a ello hay que añadir que, a la hora de visitar las casas de baños, todo conduce a pensar que, al menos en el caso de Córdoba, a raíz de los datos que hemos conseguido recabar, fueron los nobles de la ciudad los que en calidad de dueños de esas instalaciones, y como veremos en su momento, pudieron hacer un uso frecuente de esos recintos. Dos de los baños que se estudian en el presente trabajo pertenecieron a dos importantes linajes de la nobleza media cordobesa, cuyos miembros estuvieron especialmente ligados al cabildo municipal de la ciudad, mientras que el tercero tuvo como propietaria a una familia de la nobleza señorial de Córdoba. Dedicaremos las siguientes páginas a conocer la historia de estos recintos que formaron parte del paisaje urbano cordobés a finales del Medievo.

\section{El baño de Juan Ponce}

Gracias a los testimonios de diversa naturaleza que se han conservado, conocemos con mucha precisión el lugar en el que se emplazaba este baño. Así, por una parte, en un documento de 1406 se indica que estaba situado en las inmediaciones de la Puerta de Almodóvar, ${ }^{24}$ lo que nos permite ubicarlo en el sector noroeste de la collación cordobesa de Santa María, ${ }^{25}$ emplazada en la Villa ${ }^{26}$ o zona occidental de Córdoba. ${ }^{27}$ Por

\footnotetext{
21 La fecha consta en Bernardo DE Gordonio, Lilio de medicina, ed. John Cull y Brian Dutton, Hispanic Seminary of Medieval Studies, Madison, 1991, pp. I-II.

22 Bernardo DE GoRdonio, Obras de Bernardo de Gordonio, insigne maestro y doctor de Medicina, en que se contienen los siete libros de la Práctica o Lilio de la medicina, las Tablas de los ingenios de curar las enfermedades, el Regimiento de las agudas, el Tratado de los niños y Regimiento del ama y los Pronósticos, Madrid, 1697, p. 303.

23 También incluye una tercera modalidad a la que él denomina "parru", que se podía llevar a cabo de varias formas (Ibidem, p. 304).

24 Luis de Maraver y Alfaro, Historia de Córdoba, t. 10, rollo B-30. 1406.03.18. Se trata de un manuscrito que se puede consultar en la Biblioteca Municipal de Córdoba. Aunque salvo algunas excepciones el manuscrito no presenta foliación, los documentos se pueden localizar fácilmente por el rollo del microfilm y por el año.

${ }_{25}$ Sobre la ubicación de esta puerta en la collación de Santa María, ver José Manuel Escobar CAmacho, Córdoba en la Baja Edad Media (Evolución urbana de la ciudad), ed. Caja Provincial de Ahorros de Córdoba, Córdoba, 1989, plano de la p. 125.

26 Acerca de esta collación, ver Ibidem, pp. 123-149.

27 Sobre los dos sectores urbanos en los que estaba dividida Córdoba en la Baja Edad Media, ver Ibidem, p. 54 , p. 59 y plano de la p. 56.
} 
otra parte, la pertenencia a la familia Hinestrosa de este baño, que era colindante con sus casas principales, ${ }^{28}$ facilita su localización con mayor exactitud. Lamentablemente, como ha sucedido con muchas de las casas solariegas pertenecientes a la nobleza bajomedieval cordobesa, ${ }^{29}$ no ha llegado hasta nuestros días la residencia de la familia Hinestrosa, aunque podemos conocer el lugar donde pudo estar situada. De hecho, en las proximidades de la Puerta de Almodóvar, en pleno barrio de la Judería cordobesa, todavía susbiste una calleja sin salida que arranca de la calle Almanzor -en realidad esa calleja recibe también este mismo nombre- la cual, según señaló en su día T. Ramírez de Arellano, "se llamó en lo antiguo de los Henestrosas", ya que en ese sitio existía una de las casas de este linaje. Aunque el citado autor no añade ningún dato más al respecto, ${ }^{30}$ es muy probable que esas casas a las que hace referencia fuesen la propia residencia solariega de la familia Hinestrosa, que, según parece, y como vamos a ver a continuación, tenía una larga historia.

Todo conduce a pensar que este inmueble había pertenecido con anterioridad a Juan Ponce de Cabrera -nos referiremos a él más adelante- $y$, afortunadamente, conocemos su localización. Así, en un establecimiento hotelero situado muy cerca de la calleja citada, ${ }^{31}$ todavía se conserva una puerta que era, al parecer, la puerta trasera de las casas mayores de Juan Ponce de Cabrera. ${ }^{32}$ Además, un testimonio referido al año 1396 las sitúa "frente de la Judería", ${ }^{33}$ ubicación que coincide con la situación de la puerta anteriormente mencionada. ${ }^{34}$ Unos años después, en 1409, fue donado el apartado principal de esa vivienda a Leonor López de Córdoba, ${ }^{35}$ uno de los personajes clave

28 Archivo Histórico Provincial de Córdoba (AHPC), Protocolos Notariales (PN), 14-04(04), cuad. 3, fol. 21r. 1466.09.01. Los legajos de protocolos notariales del Archivo Histórico Provincial de Córdoba han cambiado de signatura en tres ocasiones. Nosotros vamos a indicar el número del legajo según la primera signatura que se asignó a esos fondos documentales y, a continuación, entre paréntesis, el número del legajo según la segunda signatura. En el archivo existen unas tablas que permiten hacer la equivalencia entre las signaturas antiguas y la signatura actual.

29 Ver, sobre este tema, Margarita CABrera SÁnchez, "La vivienda noble en Córdoba durante el siglo XV", Córdoba en la Historia: la construcción de la urbe, Francisco García Verdugo y Francisco Acosta Ramírez (coords.), ed. Ayuntamiento de Córdoba y Fundación "la Caixa", Córdoba, 1999, pp. 263-270.

30 Teodomiro Ramírez de Arellano y Gutiérrez, Paseos por Córdoba o sean apuntes para su historia, ed. Everest, Córdoba, 1995, p. 570. Como se puede comprobar en el detallado plano de J. M. Escobar, se trata de la primera calleja que arranca a la izquierda de la calle Juan Ponce, tal y como se accede a ella desde la Puerta de Almodóvar (José Manuel Escobar Camacho, Córdoba en la Baja Edad Media..., plano de la p. 125). La calle Juan Ponce es la actual Almanzor (Ibidem, p. 148).

31 Se trata del hotel La llave de la Judería.

32 Esta puerta, con el aspecto que tenía hace años, puede verse en una fotografía recogida en Francisco Ruano, Casa de Cabrera en Córdoba, ed. Concepción Muñoz Torralbo y Soledad García-Mauriño Martínez, Excma. Diputación Provincial de Córdoba, Córdoba, 1994, p. 116. En el pie de foto se indica que era la puerta trasera de las casas mayores de Juan Ponce de León (Ibidem), aunque, como puede comprobarse en el texto, se trata del mismo individuo que se llamó Juan Ponce de Cabrera (Ibidem, p. 116 y p. 120).

33 Archivo de la catedral de Córdoba (ACC), Capillas y capellanías, caja 7027, fol. 28r.

34 Sobre el emplazamiento de la Judería cordobesa, ver José Manuel Escobar CAmacho, Córdoba en la Baja Edad Media ..., plano de la p. 125.

35 AHPC, libro 7088, Inventario judicial de papeles del archivo de la casa y mayorazgo de D. José Fernández de Córdoba y Teruel, señor de Teba, 1409.11.16. Se trata de un inventario sin foliación. 
del linaje Hinestrosa y de la que nos ocuparemos detenidamente en su momento. Todo parece indicar que esas casas, que habían pertenecido a Juan Ponce, pasaron luego a ser el edificio principal asociado al mayorazgo de la familia Hinestrosa, ya que, aunque en el documento de fundación de este último, fechado en 1422, no se alude al antiguo propietario, ${ }^{36}$ tenemos constancia de que tanto las casas de Juan Ponce como las del mayorazgo del linaje Hinestrosa fueron conocidas como "del rey Almanzor", ${ }^{37}$ lo cual pone de manifiesto que debía de tratarse del mismo inmueble.

En todo caso, la ubicación de estas casas en el entorno de la calleja anteriormente mencionada nos permite emplazar el baño en esta misma zona, dado que colindaba con las casas principales del linaje Hinestrosa, según consta en la documentación notarial de la segunda mitad del siglo $\mathrm{XV} .{ }^{38}$ Además, los trabajos arqueológicos que se han realizado en las últimas décadas junto a la callejuela citada apuntan en la misma dirección. En 1993, el resultado de unas excavaciones permitió imaginar la presencia de unos baños en este emplazamiento o en sus proximidades, dado que estos últimos requerían "de una infraestructura hidráulica adecuada, que podría estar en estrecha relación con la alberca encontrada en el solar en estudio". ${ }^{39}$ Más recientemente, en el año 2007, en el transcurso de otras excavaciones llevadas a cabo en esa misma calleja, se descubrió ese mismo tipo de infraestructuras. ${ }^{40}$ En definitiva, gracias al análisis de los testimonios escritos y arqueológicos hemos podido plantear, sobre el trazado de la Córdoba actual, la posible localización de este baño, tal y como puede verse en el plano $\mathrm{n}^{\mathrm{o}} 1$ de nuestro trabajo. Nos inclinamos a pensar que las citadas instalaciones de baños databan de la etapa de dominio islámico de la ciudad, ya que gracias a los primeros trabajos arqueológicos realizados sabemos que la mencionada alberca era de época califal, ${ }^{41}$ en tanto que las excavaciones más recientes fechan en la etapa musulmana las estructuras de tipo hidráulico encontradas. ${ }^{42}$ Sin embargo, las fuentes disponibles no nos ayudan a reconstruir, con la precisión que desearíamos, la historia de este baño desde la reconquista de la ciudad hasta comienzos de la segunda década del siglo XV.

\footnotetext{
36 Real Academia de la Historia (RAH), Colección Salazar, Ms. M-53, fol. 119r. 1422.08.11. s.1.

37 Es lo que especifica F. Ruano al citar las casas mayores de Juan Ponce (Francisco RuANO, Casa de Cabrera en Córdoba, ed. cit., p. 116) y el rótulo de un cuaderno que precede a la documentación referida a las casas que habían pertenecido a la familia Hinestrosa y en el que puede leerse que las que formaron parte del mayorazgo del linaje fueron conocidas con ese nombre (AHPC, libro 7088, Inventario judicial de papeles del archivo de la casa y mayorazgo de D. José Fernández de Córdoba y Teruel, señor de Teba). Desconocemos por qué se denominaba así el inmueble, aunque imaginamos que tal vez tenga alguna relación con el hecho de que, en opinión de B. Sánchez de Feria, el palacio de Almanzor estuvo situado en la calle del mismo nombre (Bartolomé SÁnchez de FERIA, Palestra sagrada o memorial de santos de Córdoba con notas y reflexiones críticas sobre los principales sucesos de sus historias, t. 1, Córdoba, 1772, p. 133).

38 AHPC, PN, 14-04(04), cuad. 3, fol. 21r. 1466.09.01.

39 Nuria López Rey, "Informe sobre la I.A.U. en la calle Almanzor n. 20 de Córdoba”, Anuario Arqueológico de Andalucía 1993. Actividades de urgencia, Sevilla, 1997, p. 115.

40 Carmen Gómez Lara, "Actividad Arqueológica Preventiva en la calle Almanzor n 18 de Córdoba", Anuario Arqueológico de Andalucía (en prensa).

41 Nuria LóPEz Rey, "Informe sobre la I.A.U. en la calle...", p. 113.

42 Carmen Gómez Lara, “Actividad Arqueológica Preventiva en la calle...”.
} 
Pese a todo, parece evidente que la instalación perteneció al mencionado Juan Ponce, si tenemos en cuenta un documento de 1412, en el que se alude al baño que llevaba su nombre, ${ }^{43}$ así como la documentación notarial de la segunda mitad del siglo XV, en la cual el inmueble aparece citado como "las casas baño que se dise de Juan Ponçe". ${ }^{44}$ Pensamos que este último debe de ser el individuo de ese nombre que fue alcaide de Cabra $^{45}$ y Adelantado de la Frontera, ${ }^{46}$ que Alfonso XI ordenó decapitar, en 1326, al parecer, según refiere la crónica del rey, porque no quiso entregar al monarca el castillo de Cabra y, además, "puso grand alborozo en la ciubdat de Córdoba en el tiempo de las tutorías". ${ }^{47}$ Aunque no poseemos más datos verdaderamente fiables sobre él, su elevada posición social se hace patente al analizar las conexiones familiares de algunos de sus descendientes con miembros de la realeza y de la alta nobleza. Así, nos consta que, fruto de su matrimonio con Inés Enríquez, nacieron, al menos, dos hijos: Pedro Ponce, que posiblemente murió siendo niño, ${ }^{48}$ y Sancha Ponce. ${ }^{49}$ Esta última, al otorgar su testamento en el invierno de 1381, designó como heredera a Juana Enríquez, hija suya y de Fernando Enríquez, primo de Enrique II, esposa de Juan Alfonso de Guzmán, conde de Niebla. ${ }^{50}$ En

43 AHPC, libro 7088, Inventario judicial..., 1412.09.24.

44 AHPC, PN, 14-04(04), cuad. 3, fol. 21r. 1466.09.01.

45 Crónica de Alfonso XI, t. 66, ed. BAE, Madrid, 1953, p. 211.

46 RAH, Colección Salazar, Ms. I-39, fol. 25r. 1324.11.19. Córdoba.

47 Crónica de Alfonso XI, t. 66, ed. cit., p. 211.

48 En realidad, sólo hemos encontrado una mención referida a él en un documento de 1324 (RAH, Colección Salazar, Ms. I-39, fol. 25r. 1324.11.19. Córdoba), a lo que hay que añadir que, según algunos testimonios, los hijos varones del matrimonio fallecieron siendo niños (ACC, Capillas y capellanías, caja 7027, fol. 29r.).

49 ACC, Capillas y capellanías, caja 7027, fol. 28r.

50 Luis de Maraver y Alfaro, Historia de Córdoba, t. 8, rollo B-29. 1381.02.27. A este matrimonio hace referencia, en su magnífico libro sobre el linaje Guzmán, M. A. Ladero, quien añade que Juan Alfonso de Guzmán se casó en segundas nupcias con Beatriz Ponce. Sin embargo, según afirma el citado autor, este último enlace tuvo lugar en torno al año 1374 (Miguel Ángel Ladero QuesadA, Guzmán. La casa ducal de Medina Sidonia en Sevilla y su reino (1282-1521), ed. Dykinson, Madrid, 2015, p. 62), lo cual parece entrar en contradicción con la información proporcionada en el testamento de la madre de Juana, otorgado en 1381, gracias al cual sabemos que Juana estaba viva en ese momento (Luis DE MARAVER y Alfaro, Historia de Córdoba, t. 8, rollo B-29. 1381.02.27). Beatriz vivía en 1409, ya que otorgó testamento este último año (Miguel Ángel Ladero Quesada, Guzmán. La casa ducal..., p. 70) y, por tanto, no hay duda de que, como ya se ha indicado, fue la segunda mujer del conde de Niebla, aunque es evidente que el matrimonio entre ambos debió de celebrarse con posterioridad a 1381, lo que nos llevaría incluso a retrasar el nacimiento del hijo de ambos, Enrique, que, según Pedro Barrantes, tuvo lugar en 1375 (Pedro Barrantes Maldonado, Ilustraciones de la Casa de Niebla, ed. Federico Devis Márquez, Universidad de Cádiz. Servicio de Publicaciones, Cádiz, 1998, p. 245). Tal vez la explicación a todo ello se encuentre en varios testimonios documentales, según los cuales, Enrique vino al mundo bastantes años más tarde. Así, por ejemplo, en un documento fechado en 1396 se especificaba que Enrique y Teresa de Orozco contraerían matrimonio cuando alcanzasen la edad necesaria (Archivo Ducal de Medina Sidonia, leg. 841, 1396.05.28. Sevilla. Documento citado por Miguel Ángel Ladero Quesada, Guzmán. La casa ducal..., p. 91, nota 7), información que se contradice con la fecha de nacimiento de Enrique ya citada, puesto que, si había nacido en 1375, es obvio que, en 1396, tendría 21 años, edad más que suficiente para casarse, sobre todo teniendo en cuenta lo precoces que eran los enlaces matrimoniales entre los nobles de la época. Pero es que, además, en un testimonio documental de marzo de 1405 se indica que Enrique tenía, en ese momento, 14 años y, en unas anotaciones que se hacen a este documento, se 
el citado testamento no se hace referencia al baño, aunque cabe imaginar que este último, que probablemente Sancha había heredado de su padre, pudo pasar luego a su hija Juana. Sí tenemos constancia de que el inmueble acabó siendo propiedad del cabildo de la catedral de Córdoba, ya que, en 1412, algunos de sus miembros cedieron a Leonor López de Córdoba el baño y tres apartados situados en las casas de Juan Ponce, a cambio de varios inmuebles que poseía Leonor. ${ }^{51}$ Precisamente contamos con un testimonio documental en el que se especifica que, en 1396, tras el fallecimiento del conde de Niebla, Juan Alfonso de Guzmán, y con motivo del establecimiento de una capellanía en la catedral, el cabildo se convirtió en propietario de tres pares de casas colindantes con las casas mayores que habían pertenecido a Juan Ponce, ${ }^{52}$ que tal vez pudieran ser los tres apartados citados en el documento anterior. ${ }^{53}$ Sin embargo, en ese testimonio referido al año 1396 no se alude al baño, ${ }^{54}$ por lo que no sabemos si ya en ese momento formaba parte de los bienes del cabildo catedralicio o si pasó a formar parte de ellos a partir de esa fecha, posiblemente tras la muerte del conde de Niebla, al que cabe suponer heredero de los bienes de Juana, su primera esposa, dado que la pareja no tuvo descendencia. ${ }^{55}$

Gracias a los testimonios documentales mencionados anteriormente, resulta evidente que, en pocos años, Leonor López se hizo con una parte del patrimonio inmobiliario de Juan Ponce, en concreto, con sus casas solariegas y con el baño anejo a éstas. Como tendremos ocasión de comprobar a continuación, tanto este último como la vivienda quedaron en poder de los descendientes de Leonor, al menos, hasta finales del siglo XV y posiblemente durante mucho más tiempo, dado que formaron parte de uno de los mayorazgos de la familia. Aunque no podemos detenernos a analizar con detalle la vida de Leonor López de Córdoba, sí debemos recordar que es una de las figuras femeninas más interesantes de la historia de la citada ciudad. Hija del maestre Martín López de Córdoba, nos legó un minucioso relato autobiográfico en el que describe las vicisitudes por las que atravesó su familia, fiel a la causa petrista, tras el fallecimiento de Pedro el Cruel y el advenimiento de la nueva dinastía. ${ }^{56}$ Su muerte tuvo lugar en Córdoba en el verano de $1430^{57}$ y nos consta que, ocho años antes, había legado a su hijo Martín López de Hinestrosa, en concepto de mayorazgo, "unas casas, las maiores,

especifica, de forma explícita, que los cumplió el 20 de febrero de ese año (RAH, Colección Salazar, Ms. D-10, fol. 84v. 1405.03.04. Llerena). Por tanto, según esta información, había nacido en 1391.

51 AHPC, libro 7088, Inventario judicial..., 1412.09.24.

52 ACC, Capillas y capellanías, caja 7027, fol. 28 r.

53 AHPC, libro 7088, Inventario judicial..., 1412.09.24.

54 ACC, Capillas y capellanías, caja 7027, fol. 28r.

55 A este matrimonio se refiere Miguel Ángel Ladero Quesada, Guzmán. La casa ducal..., p. 62.

56 Ver, por ejemplo, una edición muy reciente: Las Memorias de Doña Leonor López de Córdoba, ed. Blas Sánchez Dueñas, Asociación cultural Andrómina, Córdoba, 2013. Sobre Leonor López y su familia, puede verse Margarita CABRERA SÁNCHez, "El destino de la nobleza petrista: la familia del maestre Martín López de Córdoba”, En la España Medieval, 24 (2001), pp. 195-238.

57 Otorgó su segundo codicilo el día 3 de julio de 1430 (AHPC, libro 7088, Inventario judicial..., 1430.07.03). Había muerto ya el día 11 (AHPC, libro 7088, Inventario judicial..., 1430.07.11). 
con el baño". ${ }^{58}$ Posteriormente, el baño pasó a ser propiedad del hijo varón de este último, Luis de Hinestrosa, regidor del concejo cordobés, ${ }^{59}$ que consta como dueño del mismo en la segunda mitad del siglo $\mathrm{XV} .{ }^{60}$ Luis de Hinestrosa es uno de los nobles cordobeses mejor documentados de su época, hasta el punto de que podemos conocer con detalle su trayectoria vital. Sabemos que nació en el año $1446^{61}$ y que murió en 1504 o en $1505 .{ }^{62} \mathrm{Su}$ enlace matrimonial con Constanza Ponce de León, nieta de Juan Ponce de León, conde de $\operatorname{Arcos},{ }^{63}$ pone de manifiesto su elevada categoría social. De igual modo, la capacidad económica de la que llegó a disfrutar se hace patente al analizar los numerosos bienes de todo tipo que engrosaron su patrimonio: cortijos, una huerta, casas e instalaciones de tipo industrial, todo lo cual se completaba con la posesión de algunos juros..$^{64} \mathrm{Y}$ entre todos esos bienes, como ya se ha indicado, se encontraba el baño.

Afortunadamente, contamos con varios documentos notariales de los años sesenta y setenta del siglo XV en los que el baño era cedido en arrendamiento, lo cual es un testimonio del control que los miembros de la oligarquía urbana solían ejercer sobre las instalaciones industriales, respecto de las cuales se seguía una explotación de tipo rentista. ${ }^{65}$ Esa documentación nos ayuda a imaginar, en primer lugar, cómo pudo ser el funcionamiento de la citada instalación. Así, por ejemplo, dada la necesidad de agua que requerían estos establecimientos dedicados a la higiene, el baño se alquilaba, según se especifica en los contratos de arrendamiento que se han conservado, junto a la casa llamada de la alcabala "do está el poso añora del agua que vyene al dicho baño". ${ }^{66}$ Gracias a uno de estos contratos, sabemos que la persona que tomó el baño en arrendamiento -se trató de una mujer llamada Elvira Rodríguez- debía encargarse de la reparación de "los caños del agua" procedente de la citada noria. ${ }^{67}$ Desconocemos el emplazamiento de la casa de la alcabala, aunque sí nos consta que pertenecía a la familia Hinestrosa desde

58 Su hija, Leonor de Hinestrosa, fue beneficiaria de otro mayorazgo (RAH, Colección Salazar, Ms. M-53, fol. 119r. 1422.08.11. s.1.).

59 AHPC, PN, 14-08(11), cuad. 1, fol. 2v. 1475.04.06.

60 AHPC, PN, 14-04(04), cuad. 3, fol. 21r. 1466.09.01; AHPC, PN, 14-08(11), cuad. 1, fol. 2v. 1475.04.06.

${ }_{61}$ Su madre se encontraba embarazada de él en abril de ese año (Luis de MARAVER y Alfaro, Historia de Córdoba, t. 10, rollo B-30. 1446.04.01).

62 Hizo testamento en junio de 1504 (Luis de Maraver y Alfaro, Historia de Córdoba, t. 13, rollo B-33, fol. 23r. 1504.06.10) y había muerto ya en junio del año siguiente (Luis de Maraver y Alfaro, Historia de Córdoba, t. 14, rollo B-34. 1505.06.03). Su prosopografía completa aparece recogida en Margarita CABRERA SÁncheZ, "El destino de la nobleza petrista: la familia...", pp. 218-220.

63 Rafael SÁnchez Saus, Linajes sevillanos medievales, vol. 2. Árboles genealógicos, ed. Ediciones Guadalquivir, Sevilla, 1991, p. 416 y pp. $402-403$ e Ibidem, vol. 1. Estudios históricos, ed. Ediciones Guadalquivir, Sevilla, 1991, p. 234. Nos consta que ya estaban casados en 1470 (AHPC, PN, 14-06(06), cuad. 3, fol. 60r. 1470.04.19).

64 El análisis pormenorizado de todos sus bienes se puede ver en Margarita CABrera SÁnchez, "El destino de la nobleza petrista: la familia...", pp. 223-234.

65 Ver, sobre este tema, Margarita CABRera SÁnChez, Nobleza, oligarquía y poder en Córdoba al final de la Edad Media, ed. Servicio de Publicaciones de la Universidad de Córdoba y Obra Social y Cultural de Cajasur, Córdoba, 1998, pp. 228-253.

${ }_{66}$ AHPC, PN, 14-04(04), cuad. 3, fol. 21r. 1466.09.01. También se alquilaban de forma conjunta esos dos inmuebles en el contrato fechado en 1475 (AHPC, PN, 14-08(11), cuad. 1, fol. 2v. 1475.04.06).

${ }_{67}$ AHPC, PN, 14-04(04), cuad. 3, fol. 21r. 1466.09.01. 
hacía muchas décadas, ya que Leonor López de Córdoba figura como propietaria de ella en $1410 .{ }^{68}$ Además, este último inmueble colindaba con las casas "de la masmorra", 69 que, al igual que la anterior, hacía tiempo que eran propiedad de la misma familia, dado que formaron parte del mayorazgo de Martín López de Hinestrosa. ${ }^{70}$

En los contratos de arrendamiento fechados en 1475 y en 1466 se alude a un elemento imprescindible en este tipo de recintos para calentar el agua: la caldera. En el primero de esos documentos se indicaba que los arrendatarios debían "echar escudo a la caldera", es decir, ponerle fondo, mientras que el propietario, Luis de Hinestrosa, tenía que "dar buelta a la caldera" $"$ " o lo que es lo mismo, repararla- y esta misma condición queda recogida también en el segundo testimonio documental mencionado. ${ }^{72}$ Además, en el documento de 1475 se especificaba que el matrimonio que tomó en alquiler la instalación estaba obligado a limpiar "las costaneras" del baño. ${ }^{73}$ Por otro lado, nos consta que se dejaron, a disposición de los arrendatarios, "tres dosenas de lebrillos de barro" ${ }^{\text {"74 }} \mathrm{y}$ "un cubo pequeño de madera con que sacan agua de la caliente", ${ }^{75}$ utensilios que, como es obvio, resultaban necesarios en este tipo de instalaciones. El recinto contaba con una persona encargada de calentar el agua, ya que hemos podido comprobar que en el documento de 1466 aparece citado, entre los testigos, Juan de la Serena, "calentador en el dicho baño". ${ }^{76}$

Por otra parte, en las actas notariales citadas se hacía referencia al uso gratuito del baño por parte de algunos miembros de la familia propietaria del mismo y de ciertas personas de su círculo doméstico. Por ejemplo, en el documento de 1466 se aludía a los baños que, de forma gratuita, podían tomar en el recinto Luis de Hinestrosa, su madre y su esposa, así como las mujeres que formaban parte del servicio doméstico del dueño y de su madre, Beatriz de Quesada. ${ }^{77}$ Es evidente que, para todos ellos, teniendo en cuenta la inexistencia de instalaciones destinadas a la higiene en las viviendas de aquella época, debía de ser un lujo la utilización de ese baño y, sobre todo, poder hacerlo de

68 AHPC, libro 7088, Inventario judicial..., 1410.06.26.

69 AHPC, PN, 14-08(11), cuad. 1, fol. 2v. 1475.04.06.

70 Así lo especifica en su testamento (Luis de Maraver y Alfaro, Historia de Córdoba, t. 10, rollo B-30. 1446.03.01).

71 AHPC, PN, 14-08(11), cuad. 1, fol. 2v. 1475.04.06.

72 AHPC, PN, 14-04(04), cuad. 3, fol. 21r. 1466.09.01.

73 Tal vez haga referencia a los costados del baño.

74 AHPC, PN, 14-08(11), cuad. 1, fol. 2v. 1475.04.06.

75 AHPC, PN, 14-04(04), cuad. 3, fol. 21r. 1466.09.01.

76 AHPC, PN, 14-04(04), cuad. 3, fol. 21r. 1466.09.01. La figura del calentador también está documentada en algunos baños de Tudela (David AlEgría Suescun, "Baños urbanos del patrimonio real en Navarra (siglos XII-XIV)", Usos sociales del agua en las ciudades hispánicas a fines de la Edad Media, María Isabel del Val Valdivieso (coord.), ed. Secretariado de Publicaciones e Intercambio Editorial. Universidad de Valladolid, Valladolid, 2002, pp. 346-348 y p. 352). No sabemos si tendría alguna relación con el señor del baño del que hay constancia en algunos fueros (Leopoldo Torres BALBÁs, Algunos aspectos del mudejarismo urbano medieval, ed. Real Academia de la Historia, Madrid, 1954, p. 58).

77 AHPC, PN, 14-04(04), cuad. 3, fol. 21r. 1466.09.01. Hemos podido comprobar que en el acta notarial de 1475 no se especifica que Luis de Hinestrosa ni su madre pudiesen hacer uso gratuito del baño, sino sólo las mujeres del servicio doméstico de ambos y la esposa de Luis de Hinestrosa (AHPC, PN, 14-08(11), cuad. 1, fol. 2v. 1475.04.06). 
forma cómoda y casi sin tener que desplazarse, dado que, como ya se indicó, el recinto colindaba con las casas principales de la familia. ${ }^{78}$ Pero, además, en esos documentos notariales se especificaba que los arrendatarios debían mantener el baño "poblado", 79 aunque la falta de datos impide conocer quiénes eran realmente las personas que frecuentaban este lugar, si bien, cabe imaginar que, muy probablemente, el baño tuvo un uso público. De cualquier modo, desconocemos si se establecieron días específicos de utilización para hombres, mujeres y judíos, tal y como sucedía en algunos baños de carácter público de otros lugares de la Península y se puede constatar en los fueros. ${ }^{80}$ El fuero de Córdoba no proporciona ningún dato al respecto, ${ }^{81}$ aunque es muy factible que se estableciese esa separación porque el baño de Juan Ponce se encontraba muy próximo al barrio judío. ${ }^{82}$ En cualquier caso, nos consta que el inmueble se alquiló por 5.800 maravedíes anuales en 1466 y por una renta anual de 7.000 maravedíes y siete pares de gallinas en el contrato establecido nueve años más tarde, estipulándose el plazo de arrendamiento en siete y tres años respectivamente. ${ }^{83}$

El baño de Juan Ponce no ha llegado a nuestros días, aunque al final de la calleja sin salida que arranca de la calle Almanzor, en el lugar aproximado en el que pudo estar emplazado, se han edificado recientemente unos baños de estilo árabe que, en cierto modo, y pese a que en ellos apenas quedan restos de antiguas estructuras, permiten evocar el antiguo baño. Sin embargo, son las fuentes notariales las que aportan algunos datos que nos ayudan a intuir, en cierto modo, cómo podía ser ese edificio a fines del siglo XV. Por una parte, la alusión al arreglo "de las paredes e tejados" del que se debía encargar el propietario ${ }^{84}$ nos lleva a suponer que existían varias dependencias. Posiblemente, el recinto estaría distribuido en diversas salas abovedadas y adaptadas a la diferente temperatura del agua, siguiendo el esquema tradicional de los baños árabes ${ }^{85}$ dado que, como ya se indicó, la instalación era, según las excavaciones realizadas, de ese origen. Pero, además, incluso en el caso de que el baño hubiese sufrido

\footnotetext{
78 AHPC, PN, 14-04(04), cuad. 3, fol. 21r. 1466.09.01.

79 AHPC, PN, 14-04(04), cuad. 3, fol. 21r. 1466.09.01; AHPC, PN, 14-08(11), cuad. 1, fol. 2v. 1475.04.06.

80 Aníbal Ruiz Moreno, "Los baños públicos en los fueros municipales españoles", Cuadernos de Historia de España, 3 (1945), pp. 154-155. Sobre este tema, ver también el trabajo reciente de María Isabel DEL Val Valdivieso, "Las mujeres y los baños en los fueros de la Castilla medieval", Impulsando la historia desde la historia de las mujeres. La estela de Cristina Segura, Pilar Díaz Sánchez, Gloria Franco Rubio y María Jesús Fuente Pérez (edts.), ed. Universidad de Huelva, Huelva, 2012, p. 224. También aporta datos sobre los diferentes días de uso de los baños, en función del sexo, Hans Peter Duerr, Nudité et pudeur. Le mythe..., pp. 30-34.

81 Joaquín Mellado Rodríguez, "El fuero de Córdoba: edición crítica y traducción”, Arbor, 166/654, (junio de 2000), pp. 191-231.

82 Se puede comprobar fácilmente en el plano ya citado de J. M. Escobar, ya que en él aparece perfectamente definido el límite del barrio judío y, muy cerca de este último, la calle Juan Ponce (José Manuel Escobar CAmacho, Córdoba en la Baja Edad Media ..., plano de la p. 125), que es la actual Almanzor (Ibidem, p. 148 ), en cuyas proximidades se encontraba el baño.

83 AHPC, PN, 14-04(04), cuad. 3, fol. 21r. 1466.09.01; AHPC, PN, 14-08(11), cuad. 1, fol. 2v. 1475.04.06. 84 AHPC, PN, 14-04(04), cuad. 3, fol. 21r. 1466.09.01.

85 Ver, a modo de ejemplo, la distribución de las salas de los baños árabes de Jaén (Luis BERges RoLdÁn, Baños árabes del palacio de Villardompardo. Jaén, ed. Diputación Provincial de Jaén, Jaén, 1989, pp. 117-126).
} 
algún proceso de reedificación durante la época de dominio cristiano de la ciudad, cabe suponer esa misma disposición, dado que la estructura de los baños edificados en las urbes cristianas era igual a la de los baños árabes, según puso de manifiesto, en su día, L. Torres Balbás. ${ }^{86} \mathrm{Y}$ a todo ello habría que añadir la propia distribución de los baños de estufa a la que hizo referencia Bernardo de Gordonio en su obra anteriormente citada, que responde claramente al modelo de baño árabe ${ }^{87}$ Por otra parte, contamos con un curioso documento notarial fechado en 1476 en el que se describe una ceremonia de desposorio que tuvo lugar en el citado baño "después de ora de biésperas (sic)" y que contó con la presencia de Beatriz de Quesada y de una nutrida concurrencia. La pareja que se desposó estaba formada por Juana Jiménez y Juan de Uceda. Nos consta que los padres de la novia, Alvar Fernández de Llerena y Mari García, ${ }^{88}$ residían en el baño ${ }^{89}$-de hecho, es el matrimonio al que Luis de Hinestrosa alquiló la instalación en la primavera del año anterior- $-{ }^{90}$ por lo que es lógico que la ceremonia se llevase a cabo en ese lugar, dado que, como es sabido, era habitual la celebración de desposorios en domicilios particulares, ${ }^{91}$ a lo que hay que añadir que, en este caso concreto, intuimos que se podía tratar de un escenario en el que su arquitectura y sus elementos decorativos de estética árabe tal vez lo convertían en un lugar un tanto exótico y especial y, por tanto, idóneo para enmarcar esa importante celebración nupcial.

\section{El baño de San Lorenzo}

No conocemos con la precisión que nos gustaría el emplazamiento de este baño cordobés, aunque sí podemos establecer la ubicación aproximada del mismo. Tenemos constancia de que estaba situado en la collación de San Lorenzo, ${ }^{92}$ es decir, en la Ajarquía cordobesa ${ }^{93}$ o zona oriental de la ciudad. ${ }^{94}$ Se da la circunstancia de que, al igual que sucedía con el baño de Juan Ponce, la situación de la residencia de la familia propietaria de este baño es la pista que nos conduce a la localización del mismo.

\footnotetext{
${ }^{86}$ Leopoldo Torres Balbás, Algunos aspectos..., p. 61.

87 El citado autor señalaba la existencia de "tres casas de piedra", de forma que en una de ellas "debe ser el ayre templado" y en las otras dos "más caliente" y "muy caliente" respectivamente, añadiendo que "debe morar en la primera casa vn poco, en la segunda más, en la tercera quanto ha menester" (Bernardo DE GoRDONIO, Obras de Bernardo de Gordonio, insigne maestro y doctor de Medicina, en que se contienen los siete libros de la Práctica o Lilio de la medicina, las Tablas de los ingenios de curar las enfermedades, el Regimiento de las agudas, el Tratado de los niños y Regimiento del ama y los Pronósticos, ed. cit., p. 304).

88 AHPC, PN, 14-09(12), cuad. 1, fol. 35v. 1476.02.02.

89 Así se especifica en la carta de dote otorgada el mismo día que se celebró el desposorio (AHPC, PN, 14-09(12), cuad. 1, fol. 35r. 1476.02.02).

90 En este documento, el apellido de ella es Rodríguez, lo que es, sin duda, un error (AHPC, PN, 14-08(11), cuad. 1, fol. 2v. 1475.04.06).

91 Ver, por ejemplo, AHPC, PN, 14-04(04), cuad. 14, fol. 5r. 1469.01.02.

92 AHPC, PN, 14-15(17), cuad. 4, fol. 22r. 1481.02.23.

93 Sobre esta collación, ver José Manuel Escobar Camacho, Córdoba en la Baja Edad Media ..., pp. 250-261.

94 Sobre los dos sectores urbanos en los que estaba dividida Córdoba en la Baja Edad Media, ver Ibidem, p. 54, p. 59 y plano de la p. 56.
} 
Gracias a un documento notarial fechado en 1477, sabemos que uno de los integrantes de ese grupo familiar llamado Pedro de Cárdenas había residido en unas casas ubicadas en la citada collación y que estas últimas colindaban con la calle del Baño. ${ }^{95}$ Aunque esa residencia no se ha conservado, conocemos su emplazamiento, ya que el citado Pedro de Cárdenas, al otorgar su acta testamentaria en 1475, dispuso que en ese inmueble debían residir "doze mujeres onestas", especificando que, si en el futuro esas casas se convertían en monasterio, este último debería llamarse monasterio de Santa María de Gracia, ${ }^{96}$ hecho que, finalmente, sucedió. ${ }^{97}$

Este edificio desapareció también, pero todavía se conserva parte de su portada en una plaza del barrio cordobés de San Lorenzo ${ }^{98}$ muy cerca de la parroquia del mismo nombre, lo que permite deducir que la citada calle del Baño y, por tanto, este último, se localizarían en sus proximidades. Pero desconocemos el lugar exacto de esa antigua vía urbana, dado que no existe en el callejero actual de la ciudad, así como de las propias instalaciones de baños, puesto que, al parecer, los restos de estos últimos no han salido a la luz. Pese a todo, podemos ubicar de forma aproximada su emplazamiento. Así, en el documento de 1477 anteriormente citado se indicaba que las casas de Pedro de Cárdenas eran colindantes, además de con la calle del Baño, con la calle Mayor de San Lorenzo y con la calle del Arroyo. ${ }^{99}$ Estas dos últimas son perfectamente identificables con dos vías urbanas que enmarcaban el antiguo monasterio de Santa María de Gracia por el sur y por el norte respectivamente, ${ }^{100}$ por lo que es evidente que la calle del Baño tuvo que estar situada al este o al oeste de la plaza a la que hemos hecho alusión. En el lado oriental de esta última se conserva un azulejo que recuerda que allí existió una vía urbana -la calle Portería de Santa María de Gracia- a lo cual hay que añadir que en un plano de Córdoba realizado en 1811 se sitúa, en ese mismo emplazamiento, una calle denominada Santa María. ${ }^{101}$ Existe la posibilidad de que esta última, que se encuentra muy cerca de la iglesia de San Lorenzo, fuese la antigua calle del Baño y el lugar de ubicación de este recinto destinado a la higiene, si consideramos, como hipótesis, que el baño pudiera tener un origen árabe y, por ello, una relación con la mezquita que ocupó el lugar donde se

\footnotetext{
95 AHPC, PN, 14-10(13), cuad. 13, fol. 9v. 1477.09.20.

96 Archivo Histórico del palacio de Viana (AHPV), Fondo histórico, Sección testamentos y mayorazgos, caja 114, exp. 10. 1475.01.16. Córdoba. Copia de 1723. Según señala M. Nieto en un libro muy reciente, en la citada vivienda de Pedro de Cárdenas habitó Gonzalo Fernández de Córdoba, el Gran Capitán, entre 1477 y 1479 (Manuel Nieto Cumplido, Infancia y juventud del Gran Capitán (1453-1481), ed. Diputación de Córdoba, Córdoba, 2015, pp. 210-211).

97 Teodomiro Ramírez de Arellano y Gutiérrez, Paseos por Córdoba ..., p. 59.

98 Se trata de la plaza del poeta Juan Bernier. Ver también, sobre el convento citado, Ibidem, pp. 58-60.

99 AHPC, PN, 14-10(13), cuad. 13, fol. 9v. 1477.09.20.

${ }^{100}$ La calle Mayor de San Lorenzo es la actual Santa María de Gracia (José Manuel Escobar Camacho, Córdoba en la Baja Edad Media ..., p. 255). La calle del Arroyo es, sin duda, la calle Arroyo de San Rafael, que aparece enmarcando el citado monasterio por el norte en un plano de Córdoba realizado en 1811 (Plano de los Franceses de Córdoba, realizado por el barón de Karvinsky y Joaquín Rillo en 1811. El original se custodia en la Gerencia Municipal de Urbanismo de la ciudad). Sin embargo, en la actualidad, la calle Arroyo de San Rafael discurre al lado de la plaza del poeta Juan Bernier. Ver el plano $\mathrm{n}^{\circ} 2$ de nuestro trabajo.

101 Plano de los Franceses de Córdoba.
} 
construyó el mencionado templo. ${ }^{102}$ Sin embargo, no queremos dejar de señalar que, en el lado occidental de la plaza, se sitúa una calle llamada Pleitineros, que también figura en el plano de $1811,{ }^{103}$ aunque desconocemos si existió en la época bajomedieval y, por tanto, si pudo ser la calle del Baño. En cualquier caso, todos estos datos nos han permitido plantear la posible localización de este baño sobre el actual trazado urbano de Córdoba, tal y como puede verse en el plano $\mathrm{n}^{\circ} 2$ de nuestro trabajo.

No conocemos el origen del baño al que estamos aludiendo, ya que, aunque M. Muñoz lo consideró de origen árabe, no aporta ningún testimonio documental que pruebe realmente la cronología del mismo. ${ }^{104}$ De hecho, los primeros testimonios que hemos conseguido recopilar referentes a él datan de las últimas décadas del siglo XV. Por ejemplo, se citan "las casas e vaño de Sant Lloreinte", es decir, de San Lorenzo, en un documento de 1481, gracias al cual sabemos también que su propietario había sido el ya citado Pedro de Cárdenas. ${ }^{105} \mathrm{Al}$ parecer, según se especifica en su testamento, fechado seis años antes, Pedro de Cárdenas compró parte de ese baño para su esposa a cargo de la herencia que ésta recibió de su padre y en el documento se indica que el vendedor fue un individuo llamado Fernando de Gahete y que Pedro de Cárdenas era propietario de otra parte de esa instalación. ${ }^{106}$

Antes de ocuparnos del baño, merece la pena detenerse a analizar la figura de Pedro de Cárdenas, ya que fue un importante miembro de la nobleza cordobesa vinculado de manera especial a los Fernández de Córdoba y, en concreto, a los señores de Aguilar. De hecho, consta como criado de Pedro Fernández de Córdoba, señor de esta villa señorial, en $1455^{107} \mathrm{y}$, muy probablemente, es el individuo homónimo que está documentado como vasallo del rey y alcaide de Aguilar en $1443 .{ }^{108} \mathrm{~A}$ comienzos de la década de los sesenta, figura como alcalde mayor de la ciudad de Córdoba, ${ }^{109}$ lo que prueba de manera evidente su subordinación al hijo del citado Pedro Fernández de Córdoba, don Alfonso de Aguilar, que fue titular de una de las alcaldías mayores de la ciudad y se convirtió en la persona más poderosa de Córdoba durante la segunda mitad del siglo XV. ${ }^{110}$ La vinculación a este miembro de la alta nobleza cordobesa permite imaginar la posición preeminente que, sin duda, logró alcanzar Pedro de Cárdenas en el gobierno de la ciudad, dado que su oficio

\footnotetext{
102 Carmen GonzÁlez Gutiérrez, Las mezquitas de barrio de Madinat Qurtuba: una aproximación arqueológica, ed. Diputación de Córdoba, Córdoba, 2012, p. 69.

103 En este plano aparece con el nombre de calle del Pleitinero (Plano de los Franceses de Córdoba).

104 Miguel MuÑoz VÁzQuEz, "Los baños árabes ...”, apéndice sin paginación de este artículo.

105 AHPC, PN, 14-15(17), cuad. 9, fol. 5r. 1481.02.02.

106 AHPV, Fondo histórico, Sección testamentos y mayorazgos, caja 114, exp. 10. 1475.01.16. Córdoba. Copia de 1723 .

107 RAH, Colección Salazar, Ms. M-48, fol. 11v. 1455.02.18. Toledo.

108 RAH, Colección Salazar, Ms. M-46, fol. 232v. 1443.06.27. s.1.

109 AHPC, PN, 14-03(03), cuad. 7, fol. 26v. 1461.10.06.

110 Margarita CABrera SÁnchez, Nobleza, oligarquía y poder en Córdoba ..., p. 83. En su testamento, Pedro de Cárdenas dejaba constancia de que era alcalde mayor de la ciudad en nombre de don Alfonso (AHPV, Fondo histórico, Sección testamentos y mayorazgos, caja 114, exp. 10. 1475.01.16. Córdoba. Copia de 1723).
} 
de alcalde mayor lugarteniente lo compaginó con una regiduría en el concejo cordobés. ${ }^{111}$ De igual modo, se constata también la saneada situación económica de la que llegó a disfrutar, a juzgar por las numerosas propiedades de diverso tipo que formaron parte de su patrimonio. En Córdoba poseía varios cortijos, ${ }^{112}$ un lagar, ${ }^{113}$ una huerta, ${ }^{114}$ un buen número de casas, un mesón, algunas tiendas ${ }^{115} \mathrm{y}$ un horno. ${ }^{116}$ Era dueño también de numerosas propiedades en Peñaflor ${ }^{117}$ y de un juro de heredad de 20.000 maravedíes que le cedió don Alfonso de Aguilar. ${ }^{118} \mathrm{Y}$ a todo ello hay que añadir, como ya señalamos, el baño.

Tras la muerte de Pedro de Cárdenas, acaecida entre 1475 y $1477,{ }^{119}$ la mitad de esta instalación pasó a su viuda, Mari Fernández de Arenillas, según consta en un documento otorgado en $1481 .{ }^{120}$ Pero todo conduce a pensar que, poco tiempo después, esa parte del inmueble dejó de ser propiedad de esta última. Al menos, es lo que podemos deducir de la lectura de un testimonio fechado en 1484 en el que se alquilaba el baño -dándose a entender que el contrato afectaba a la totalidad del inmueble- $y$ en el cual, entre los propietarios, que eran miembros de la familia Cárdenas, no figuraba la citada señora. ${ }^{121}$ Tal vez Mari Fernández les vendió su parte de la instalación, ya que, dado que vivía en el año $1484,{ }^{122}$ es obvio que no pudieron recibirla en concepto de herencia. ${ }^{123}$

Gracias a un contrato de arrendamiento del baño que otorgaron en 1490 varias personas del linaje Cárdenas, entre ellas Juan de Cárdenas, titular de una de las juraderías de la collación de Santiago y su hermano Luis de Cárdenas, regidor del concejo cordobés, así como el hermano mayor de la cofradía de la Caridad, Juan Sánchez, ${ }^{124}$ podemos conocer

111 Consta como regidor de Córdoba en su testamento (AHPV, Fondo histórico, Sección testamentos y mayorazgos, caja 114, exp. 10. 1475.01.16. Córdoba. Copia de 1723).

112 El cortijo de Guadatín (AHPV, Fondo histórico, Sección testamentos y mayorazgos, caja 114, exp. 10. 1475.01.16. Córdoba. Copia de 1723) y el de Cárdenas (AHPC, PN, 14-15(17), cuad. 9, fol. 10r. 1481.01.28).

113 En el pago de Valdeleche (AHPV, Fondo histórico, Sección testamentos y mayorazgos, caja 114, exp. 10. 1475.01.16. Córdoba. Copia de 1723).

114 Llamada de El Marruvial (AHPC, PN, 14-15(17), cuad. 9, fol. 20v. 1481.02.28).

115 En su testamento se citan varias casas, un mesón y unas tiendas (AHPV, Fondo histórico, Sección testamentos y mayorazgos, caja 114, exp. 10. 1475.01.16. Córdoba. Copia de 1723). En un documento de 1481 se mencionan seis casas (AHPC, PN, 14-15(17), cuad. 9, fol. 20v. 1481.02.28).

116 AHPC, PN, 14-15(17), cuad. 9, fol. 20v. 1481.02.28.

117 En Peñaflor era propietario de tierras de cereal, mesones, huertas y molinos, destacando el heredamiento de La Isla (AHPV, Fondo histórico, Sección testamentos y mayorazgos, caja 114, exp. 10. 1475.01.16. Córdoba. Copia de 1723).

118 Archivo General de Simancas (AGS), Mercedes y Privilegios (MP), leg. 46, fol. 50. 1467.08.22. Córdoba.

119 Vivía en septiembre de 1475 (AHPC, PN, 18-06(01), cuad. 7, s.f. 1475.09.15). Había muerto ya dos años después (AHPC, PN, 14-10(13), cuad. 13, fol. 9v. 1477.09.20).

120 AHPC, PN, 14-15(17), cuad. 9, fol. 20v. 1481.02.28.

${ }_{121}$ AHPC, PN, 14-17(19), cuad. 5, fol. 4v. 1484.07.03.

122 Todavía vivía en septiembre de 1487 (AHPC, PN, 14-20(22), cuad. 5, fol. 35v. 1487.09.18) y había muerto ya en febrero del año siguiente (AHPC, PN, 14-21(23), cuad. 1, fol. 42r. 1488.02.23).

${ }^{123}$ Posiblemente, Pedro de Cárdenas y su esposa no tuvieron hijos o, si llegaron a tenerlos, no sobrevivieron a su padre, ya que este último, en su testamento, no menciona a ninguno (AHPV, Fondo histórico, Sección testamentos y mayorazgos, caja 114, exp. 10. 1475.01.16. Córdoba. Copia de 1723).

${ }^{124}$ Sobre esta cofradía, ver María Teresa CRIAdo Vega, Poder y actividad asistencial en la Castilla bajomedieval y moderna. La cofradía cordobesa de la Caridad, ed. Diputación de Córdoba, Córdoba, 2014. 
algunos datos relativos al funcionamiento del mismo. En esta acta notarial se menciona la existencia de una noria - esta última estaba valorada en 1.000 maravedíes-, al tiempo que se alude también a la caldera. Además, se hacía referencia a la gratuidad de la que podían disfrutar, a la hora de acudir al recinto, las esposas de los propietarios, las mujeres del servicio doméstico de estos últimos y las beatas. ${ }^{125}$ Se da la circunstancia de que, según señalamos con anterioridad, la cercanía de las instalaciones con el beaterio que fundó el alcalde Pedro de Cárdenas permitía de forma especial el acceso al baño por parte de esas beatas. En cualquier caso, no deja de ser llamativa esa entrada gratuita exclusivamente femenina y, en definitiva, esa facilidad que se daba a las mujeres para que pudieran hacer uso del baño. Por lo demás, tal y como sucedía con el baño estudiado en el epígrafe anterior, imaginamos que, muy posiblemente, el baño de la familia Cárdenas tuvo un carácter público.

Por último, gracias a la documentación conservada, sabemos que el inmueble se cedió en arrendamiento por un plazo de tiempo algo superior a un año en el contrato de 1490 y por un período de un año en el otro contrato de alquiler fechado en 1484. En ambos casos, conocemos los nombres de los arrendatarios: el matrimonio formado por Rodrigo Alfonso y Ana Rodríguez en el primero de esos contratos y una viuda llamada Marina Núñez en el segundo, estipulándose, respectivamente, una renta anual de 16.500 y 13.000 maravedíes respectivamente. ${ }^{126}$ En relación a la primera de las rentas citadas, es evidente que se trata de una cantidad elevada, sobre todo si la comparamos con lo que devengaban, en metálico, las instalaciones industriales documentadas en Córdoba a finales del siglo $\mathrm{XV},{ }^{127}$ todo lo cual parece poner de manifiesto la importancia que pudo tener este baño, parte de cuyos restos tal vez se encuentren todavía soterrados en el barrio de San Lorenzo.

\section{El baño de la casa de los señores de Santa Eufemia}

Entre los testimonios documentales consultados, hemos podido localizar la presencia de un baño en el interior de la vivienda de una familia de la nobleza señorial de Córdoba, cuyos miembros fueron señores de Santa Eufemia. En realidad, la alusión al baño que se hace en la documentación no nos permite saber si se trataba de unos baños públicos situados dentro del espacio doméstico o si era una instalación privada. Aunque, como es sabido, la existencia de un baño privado en las viviendas no era habitual durante el Medievo, ${ }^{128}$ cabe suponer que, en los ambientes palaciegos, en ocasiones, no debió de ser tan infrecuente contar con alguna dependencia de este tipo. Al menos, es lo que se puede constatar en el

\footnotetext{
125 AHPC, PN, 18-03a(04), fol. 728v. 1490.04.12.

126 AHPC, PN, 18-03a(04), fol. 728v. 1490.04.12; AHPC, PN, 14-17(19), cuad. 5, fol. 4v. 1484.07.03.

127 De hecho, hemos podido comprobar que, por los mismos años en los que se otorgó el citado contrato de arrendamiento del baño por el que se exigieron 16.500 maravedíes anuales, esta cantidad sólo es superada, en 1493 y 1489 respectivamente, por una tenería y una jabonería, cedidas en arrendamiento por 20.000 y 61.000 maravedíes anuales (Margarita CABRERA SÁNCHEZ, Nobleza, oligarquía y poder en Córdoba ..., pp. 239-253 y, en especial, tabla de la p. 247, p. 248 y nota 119$)$.

${ }_{128}$ Algunos autores señalan que, antes del siglo XIX, no existió, en las casas urbanas, nada similar al cuarto de baño (Norman John Greville Pounds, La vida cotidiana: historia ..., p. 257).
} 
caso del castillo de Tudela, en el que Juana II contaba con una sala de baño privada. ${ }^{129}$ En cambio, en el sur de Italia, al parecer, salvo algunas excepciones, no era frecuente encontrar baños en los palacios, ${ }^{130}$ lo que nos lleva pensar que, probablemente, los nobles de la época, por más que tratasen de emular a la realeza, no solían disfrutar de un lujo semejante en sus grandes mansiones. ${ }^{131}$ Por todo ello, creemos que, tal vez, como veremos con detalle más adelante, lo que existía en la vivienda de los señores de Santa Eufemia era, más que una estancia doméstica privada dedicada a la higiene corporal y mandada construir al efecto por los miembros de esa familia, un antiguo baño doméstico que pudo ser utilizado como tal por parte de estos últimos o, bien, unos baños de carácter público. La primera mención que tenemos de este baño aparece en el testamento de Pedro Carrillo, titular del señorío de Santa Eufemia, otorgado en 1422, en el cual dejaba en usufructo a su esposa, Beatriz Venegas, sus "casas mayores y huerta y baño que en ellas está". Gracias a este testimonio sabemos que la vivienda se encontraba en la collación de Santo Domingo, ${ }^{132}$ en el sector de la Villa cordobesa ${ }^{133}$ y, afortunadamente, conocemos con precisión su emplazamiento y, obviamente, la del baño. En una anotación del siglo XVIII que se inserta a continuación del testamento de Fernando Díaz, primer señor de Santa Eufemia, ${ }^{134}$ se especifica que, en 1758, esas casas fueron vendidas por el entonces conde de Santa Eufemia a una obra pía para doncellas necesitadas que había fundado el obispo de Córdoba Francisco Pacheco ${ }^{135}$ y que, según señala T. Ramírez de Arellano, fue el origen del colegio de Santa Victoria, cuya edificación comenzó pocos años después. ${ }^{136}$

Todavía se puede contemplar, en pleno centro de Córdoba, la impresionante fachada del colegio y de la iglesia aneja, ${ }^{137}$ lo que permite ubicar con exactitud la antigua casa de la familia señorial de Santa Eufemia (ver plano no 3 de nuestro trabajo). El dilatado espacio

\footnotetext{
129 David Alegría Suescun, "Baños urbanos del patrimonio real...”, p. 329.

130 Jean-Marie Martin, "Les bains dans l'Italie méridionale au Moyen Âge (VII'-XIII ${ }^{\mathrm{e}}$ siècle)", Bains curatifs et bains hygiéniques en Italie de l'Antiquité au Moyen Âge, Marie Guérin-Beauvois y Jean-Marie Martin (edts.), ed. École française de Rome, Rome, 2007, pp. 68-69. Sí se han localizado "bathing chambers", en el ámbito doméstico, en Amalfi (Jill CASKEY, "Steam and "sanitas" in the domestic realm. Baths and bathing in southern Italy in the Middle Ages", Journal of the Society of Architectural Historians, 58/2 (junio de 1999), p. 170 y, en general, todo el artículo). Ver también, sobre los baños de Amalfi, Amadeo FeniELLO, "Il bagno dei Capuano ad Amalfi (XII-XIII sec.)", Bains curatifs et bains hygiéniques en Italie de l'Antiquité au Moyen Âge, Marie Guérin-Beauvois y Jean-Marie Martin (edts.), pp. 143-151.

131 De hecho, al parecer, en París, en el año 1800, solamente contaban con cuarto de baño "una de cada tres" mansiones importantes (Georges Vigarello, Lo limpio y lo sucio. La higiene del cuerpo desde la Edad Media, ed. Alianza Editorial, Madrid, 1991, pp. 198-199).

132 RAH, Colección Salazar, Ms. M-17, fol. 16r. 1422.06.10. Córdoba.

133 Sobre esta collación, ver José Manuel Escobar CAmacho, Córdoba en la Baja Edad Media ..., pp. $178-182$.

134 Su figura se estudia en Margarita CABrera SÁnchez, Nobleza, oligarquía y poder en Córdoba..., pp. 38-40. Sobre él, ver también Emilio CABRERA MuÑoz, "Un pionero de la repoblación nobiliaria en los siglos XIII y XIV. Fernando Díaz Carrillo, señor de Santa Eufemia”, VI Estudios de frontera. Población y poblamiento. Homenaje a Manuel González Jiménez, Francisco Toro Ceballos y José Rodríguez Molina (coords.), ed. Diputación Provincial de Jaén, Jaén, 2006, pp. 151-165.

135 Archivo Ducal del Infantado (ADI), leg. 28, doc. 923. 1345.06.04. Córdoba. Copia de 1517.

136 Teodomiro Ramírez de Arellano y Gutiérrez, Paseos por Córdoba ..., p. 433.

137 Se encuentran en la calle Santa Victoria, muy cerca de la céntrica plaza de las Tendillas.
} 
que ocupa hoy ese centro escolar permite imaginar las dimensiones que pudo tener la citada residencia, a todo lo cual hay que añadir los datos que se pueden extraer de la documentación conservada. De hecho, gracias a un acta notarial fechada en 1483, sabemos que en la vivienda, perteneciente en ese momento a Gonzalo Mejía, titular del señorío, ${ }^{138}$ existía una huerta, que contaba con un "poso añora e alberca" y en la que, al parecer, tenían un especial protagonismo los naranjos. ${ }^{139}$ Pero, además, en esa residencia se incluía "una casa cosina con una chimenea", "una casa establo" y un "palaçio del agua que está çerrado", a todo lo cual hay que añadir la existencia del baño, ya que en el documento se hace alusión a "[una casa] que solía ser bañuelo que está en las dichas casas". ${ }^{40}$

A la luz de todos estos datos, resulta evidente que los señores de Santa Eufemia residieron en una mansión de gran tamaño que responde claramente al modelo arquitectónico palaciego que imperaba en la época, pero en la que, además, según ha señalado con acertadas palabras M. ${ }^{\mathrm{a}}$ I. del Val, la disponibilidad de agua en la propia casa era un "elemento que vendría a resaltar, junto a otros, el grado de prestigio y poder de su propietario". ${ }^{141}$ Precisamente, el suministro hídrico en esa vivienda señorial se conseguía gracias a la presencia de varios elementos que guardan una relación con el baño, dada la necesidad de agua abundante que requerían este tipo de instalaciones. Así, por ejemplo, el documento de 1483 alude a la existencia de un pozo-noria provisto de "sogas e acarduçes (sic) e ruedas", que incluso contaba con un caballo para la extracción del agua. Aunque, según se especifica en ese testimonio documental, el agua del pozo se utilizaba para el riego de la huerta, ${ }^{142}$ es más que probable que también se emplease para el funcionamiento del

\footnotetext{
${ }_{138}$ Sobre su figura, ver Margarita CABRera SÁnchez, Nobleza, oligarquía y poder en Córdoba ..., pp. 44-45.

139 Se trata de un documento en el que un criado de Gonzalo Mejía, llamado Diego Mejía, arrendaba a un hortelano la huerta que había en la vivienda de su señor, especificándose que en esta última se debía plantar un centenar de naranjos. Además de los naranjos, sabemos que existían más árboles, aunque el documento no especifica ningún dato más al respecto (AHPC, PN, 14-16(18), cuad. 4, fol. 11r. 1483.05.09).

140 AHPC, PN, 14-16(18), cuad. 4, fol. 11r. 1483.05.09.

141 María Isabel Del VAL VALDivieso, "Agua y organización social del espacio urbano", Usos sociales del agua en las ciudades hispánicas a fines de la Edad Media, María Isabel del Val Valdivieso (coord.), p. 36. Esta misma idea la expresa la citada autora en Agua y poder en la Castilla bajomedieval. El papel del agua en el ejercicio del poder concejil a fines de la Edad Media, ed. Junta de Castilla y León. Consejería de Cultura y Turismo, Valladolid, 2003, pp. 189-190. M. Fernández también se ha referido al hecho de que el agua "solía asociarse a inmuebles ricamente construidos" (Manuel Fernández Chávez, "El papel de nobles y conversos en la difusión del agua de pie en la Sevilla del siglo XV", Agua y sociedad en la Edad Media hispana, María Isabel del Val Valdivieso y Juan Antonio Bonachía Hernando (coords.), ed. Editorial Universidad de Granada, Granada, 2012, p. 325). Por su parte, J. A. Bonachía ha señalado que las conducciones de agua de uso privado se relacionan con miembros de la sociedad privilegiada o con algunas instituciones (Juan Antonio BonACHÍA HeRnANDO, "El agua en la documentación municipal: los "libros de actas", El agua en las ciudades castellanas durante la Edad Media. Fuentes para su estudio, María Isabel del Val Valdivieso (coord.), ed. Secretariado de Publicaciones e intercambio científico. Universidad de Valladolid, Valladolid, 1998, p. 67, nota 73). Sobre el binomio agua y poder, ver también Juan Francisco Jiménez AlcÁZAR, Agua y poder en Lorca durante la Baja Edad Media, ed. Secretariado de Publicaciones de la Universidad de Murcia, Murcia, 1996, y Hipólito Rafael Oliva Herrer, "L'eau et le pouvoir dans les villes castillanes à la fin du Moyen Âge. Palencia, un exemple de concurrence de pouvoirs", Histoire Urbaine, 22 (junio de 2008), pp. 59-75. ${ }_{142}$ AHPC, PN, 14-16(18), cuad. 4, fol. 11r. 1483.05.09. Sobre las norias de tiro y los pozos, ver Ricardo Córdoba de la Llave, “Algunas consideraciones sobre el legado...”, pp. 364-367.
} 
baño durante el tiempo que éste estuvo en uso y, por supuesto, para actividades de tipo doméstico. Pero, como ya se ha indicado, además del pozo, en el espacio doméstico se emplazaba una estructura que, respondiendo al sugerente nombre de "palaçio del agua", ${ }^{143}$ debió de tener a esta última como protagonista. Desconocemos si entre esa estructura y el baño pudo existir alguna conexión, aunque, en todo caso, y como parece denotar su nombre, posiblemente albergó algún depósito de agua que incluso pudo ser utilizado para abastecer el baño, sobre todo si tenemos en cuenta que, muy cerca de esta residencia, al norte y al sur de esta última respectivamente, se ubicaban una "casa del agua", en la que daba comienzo una canalización, ${ }^{144}$ y otro lugar de captación de agua con su canal correspondiente. ${ }^{145}$ Por tanto, y dado que parece evidente que esta zona de la ciudad contaba con acuíferos, existe la posibilidad de que los señores de Santa Eufemia pudiesen contar con provisionamiento de agua en su vivienda, lo que, desde luego, debía de ser un lujo al alcance de muy pocos. En relación con este tema, M. ${ }^{\mathrm{a}}$ I. del Val se ha referido al hecho de que el agua podía elevar el estatus social de quienes formaban parte de los concejos, sobre todo los regidores, ya que podían "beneficiarse privilegiadamente de la disponibilidad de agua" en sus hogares. ${ }^{146}$ Tal vez, el señor de Santa Eufemia, Gonzalo Mejía, desde la posición que ocupaba en el concejo cordobés -fue regidor y voto mayor-, ${ }^{147}$ llegó a disfrutar de ese privilegio. Además, se da la circunstancia de que, muchos años antes, otro miembro de la familia señorial de Santa Eufemia había promovido la realización de una canalización de agua en Córdoba, ya que, gracias al testamento de Rodrigo Mejía, señor de Santa Eufemia e hijo del citado Gonzalo Mejía, sabemos que Gómez Fernández, segundo titular del señorío y alcalde mayor de Córdoba, ${ }^{148}$ "llebó el agua desde la Puerta del Rincón por debajo de tierra hasta la casa, que, según oy día, parecía fue muy costosa y a la casa probechosa". En esta ocasión, los beneficiarios fueron los religiosos del monasterio de San Agustín, pues, como se indica en el testamento, "la casa" a la que se hace referencia era el citado monasterio. Tenemos constancia de que la capilla mayor de este monasterio fue el lugar de sepultura de una buena parte de los miembros de la familia señorial de Santa Eufemia desde la época de Fernando Díaz, ${ }^{149}$ primer titular del señorío

\footnotetext{
143 AHPC, PN, 14-16(18), cuad. 4, fol. 11r. 1483.05.09.

144 Guadalupe Pizarro Berengena, El abastecimiento de agua a Córdoba. Arqueología e Historia, ed. Servicio de Publicaciones. Universidad de Córdoba, Córdoba, 2014, p. 210. Esta casa es la que se sitúa en la calle Juan de Mena (Ibidem, plano de la p. 209).

${ }_{145}$ Este lugar de captación es el que aparece en la parte inferior izquierda del plano, dibujado con un trazo de color gris (Ibidem, plano de la p. 209). Para ubicar en este plano la casa de los señores de Santa Eufemia, basta con comparar este último con el Plano de los Franceses de Córdoba y observar el emplazamiento del colegio de Santa Victoria, que, como ya se indicó, ocupó el solar de esa vivienda.

146 María Isabel del Val VALDIVIESo, Agua y poder en la Castilla bajomedieval. El papel del agua ..., pp. 65-66.

147 Consta como regidor en un documento de 1477 (AGS, Registro General del Sello (RGS), fol. 357. 1477.11.24. Sevilla). Hemos citado el documento original procedente de la sección del Registro General del Sello que se encuentra en el portal PARES: http://pares.mcu.es/ Figura como voto mayor del concejo en 1480 (AGS, Cámara de Castilla-Pueblos, leg. 6, fol. 227. 1480.08.20. Córdoba).

${ }_{148}$ Consta como alcalde en el testamento de su padre, Fernando Díaz (ADI, leg. 28, doc. 923. 1345.06.04. Córdoba. Copia de 1517). Sobre Gómez Fernández, ver Margarita Cabrera Sánchez, Nobleza, oligarquía y poder en Córdoba..., p. 40.

149 RAH, Colección Salazar, Ms. M-17, fol. 47v. 1535.11.22. s.1.
} 
y padre de Gómez Fernández, ${ }^{150}$ por lo que es fácil imaginar que este último, en calidad de alcalde mayor de la ciudad, promoviese la ejecución de esa conducción de agua para beneficiar a los religiosos de San Agustín y, en definitiva, para mejorar la infraestructura de un edificio vinculado de forma especial al linaje.

En cualquier caso, tratando de reconstruir cómo pudo ser el baño que existió en esta residencia nobiliaria, podemos señalar que de la mención que se hace del mismo en el citado documento fechado en 1483 -en él se alude a "[una casa] que solía ser bañuelo"-, se deduce que, posiblemente, este último ya no estaba en uso en ese momento, al igual que el "palaçio del agua" del que sí que se afirma de forma clara que no se utilizaba. ${ }^{151}$ Además de ese testimonio al que acabamos de referirnos, contamos con otra mención documental fechada trece años antes en la que también se hace alusión al baño existente en el interior de ese palacio. Así, sabemos que una falsificación documental realizada a instancias de Gonzalo Mejía con el fin de obtener la jurisdicción sobre el castillo de Madroñiz, ${ }^{152}$ se llevó a cabo hacia el año 1470 "dentro en las casas del dicho señor Gonçalo Mexía, en un apartado que se dise El Bañuelo". ${ }^{153}$ La expresión que se utiliza en los documentos citados para referirse a esa instalación nos lleva a suponer que, probablemente, se tratase de un baño de pequeño tamaño, situado, tal vez, en algún lugar poco visible dentro de la enorme mansión del señor de Santa Eufemia y de ahí que se utilizase como lugar para llevar a cabo, con el mayor secreto, la falsificación anteriormente citada. Pero, en cualquier caso, es todo lo que podemos aportar sobre la posible fisonomía del recinto.

Tampoco conocemos el origen de este baño, aunque algunos testimonios permiten sospechar que pudo ser muy antiguo. Así, en la anotación del siglo XVIII anteriormente citada, se indica que, debido a su antigüedad, las casas mayores del conde de Santa Eufemia eran "conocidas por las de Séneca". ${ }^{154}$ En realidad, no se sabe en qué lugar de la ciudad de Córdoba estuvo situada la domus del célebre filósofo, aunque, teniendo en cuenta la información contenida en esa anotación, no queremos dejar de apuntar la hipótesis de que la vivienda de los señores de Santa Eufemia pudiese tener una larga historia y, si ello era así, posiblemente también fuese una construcción muy antigua el baño que se encontraba en su interior. Tal vez tuviese un origen romano, dado que el actual colegio de Santa Victoria colinda por su parte trasera con el Museo Arqueológico de Córdoba, en cuyo interior se conservan los restos del teatro romano de la ciudad. ${ }^{155}$ De hecho, teniendo en cuenta esta circunstancia y el propio nombre con el que el recinto aparece citado en las fuentes medievales, que permite imaginar un baño de reducidas dimensiones, no queremos dejar

\footnotetext{
${ }^{150}$ Margarita Cabrera SÁnchez, Nobleza, oligarquía y poder en Córdoba ..., p. 40.

151 AHPC, PN, 14-16(18), cuad. 4, fol. 11r. 1483.05.09.

152 Emilio Cabrera MuÑoz, "La jurisdicción del castillo de Madroñiz. Un caso de falsificación documental", Historia. Instituciones. Documentos, 19 (1992), p. 113. Ese castillo está situado en el lugar donde convergen las provincias de Córdoba, Ciudad Real y Badajoz.

153 Archivo Histórico Nacional, Osuna, leg. 323-4. Documento citado en Ibidem, p. 119 y p. 121.

154 ADI, leg. 28, doc. 923. 1345.06.04. Córdoba. Copia de 1517.

155 Sobre el teatro, ver Ángel Ventura Villanueva, "Edificios de espectáculo", Las capitales provinciales de Hispania, 1, Córdoba Colonia Patricia Corduba, Xavier Dupré Raventós (edt.), ed. L'Erma di Bretschneider, Roma, 2004, pp. 65-72 y, en especial, el plano de la p. 67.
} 
de apuntar la posibilidad de que último pudiera haber sido, en su origen, un baño privado de época romana, puesto que, como ya señalamos, parece poco probable que los miembros del linaje edificasen, en el recinto de la vivienda, una instalación privada de este tipo. Sin embargo, también existe la posibilidad de que se tratase de unos baños públicos integrados, de algún modo, en el inmenso recinto de la casa: unas antiguas termas, unos baños árabes o una instalación edificada en la época de dominio cristiano de la ciudad. En todo caso, cabe suponer que, en algún momento, el recinto pudo servir para atender las necesidades higiénicas de la familia señorial de Santa Eufemia. Por otra parte, todo conduce a pensar que la instalación formó parte del mayorazgo de los señores de Santa Eufemia, ya que nos consta que, en su testamento, Pedro Carrillo legaba a su hija Teresa, por vía de mayorazgo, sus casas principales, en cuyo interior, como ya se indicó, se encontraba el baño. ${ }^{156}$ Sin embargo, desconocemos cuál fue su destino, pues las últimas noticias que poseemos sobre él se pierden en los años ochenta del siglo XV. Es posible que, si ya no se utilizaba durante esta época, como parece poner de manifiesto el documento anteriormente citado, ${ }^{157}$ terminase pronto por ser abandonado y, en definitiva, por desaparecer tras el paso de los años, aunque tampoco podemos descartar que algunos de sus restos permanezcan todavía ocultos debajo del extenso solar que ocupó, en su día, la casa de los Mejía.

En conclusión, como hemos intentado poner de manifiesto en este trabajo, la consulta de la documentación notarial permite conocer algunos de los baños que existieron en Córdoba durante la Baja Edad Media y cuya historia era desconocida hasta este momento. De igual modo, hemos podido comprobar que esos establecimientos formaron parte del patrimonio de los miembros de la nobleza de la ciudad, quienes, por esa circunstancia, pudieron hacer un uso frecuente de esos recintos, lo que, probablemente, les llevó a atender de forma especial su higiene corporal, en una época en la que, como es sabido, el aseo distaba mucho de ser un gesto cotidiano. Al mismo tiempo, el posible carácter público de algunos de esos baños y la dimensión social que solían tener este tipo de instalaciones los convirtieron seguramente en lugar de encuentro de los cordobeses no privilegiados de finales del Medievo.

En definitiva, ello revela la pervivencia del uso de los baños en las postrimerías de la Edad Media, si bien, previsiblemente, en pocos años, esos establecimientos posiblemente dejaron de ser lugares frecuentados por los vecinos de la ciudad, si tenemos en cuenta la paulatina desaparición de este tipo de recintos que tuvo lugar, como es bien conocido, con la llegada de la época moderna. En nuestra opinión, el rescatar del olvido esos baños, cuyos restos tal vez puedan estar escondidos todavía bajo el suelo de Córdoba, contribuye, sin duda, a reconstruir una parte importante del pasado de la ciudad.

Fecha de recepción: 4 de febrero de 2016

Fecha de aceptación: 8 de abril de 2016

156 RAH, Colección Salazar, Ms. M-17, fol. 16r. 1422.06.10. Córdoba.

157 AHPC, PN, 14-16(18), cuad. 4, fol. 11r. 1483.05.09. 


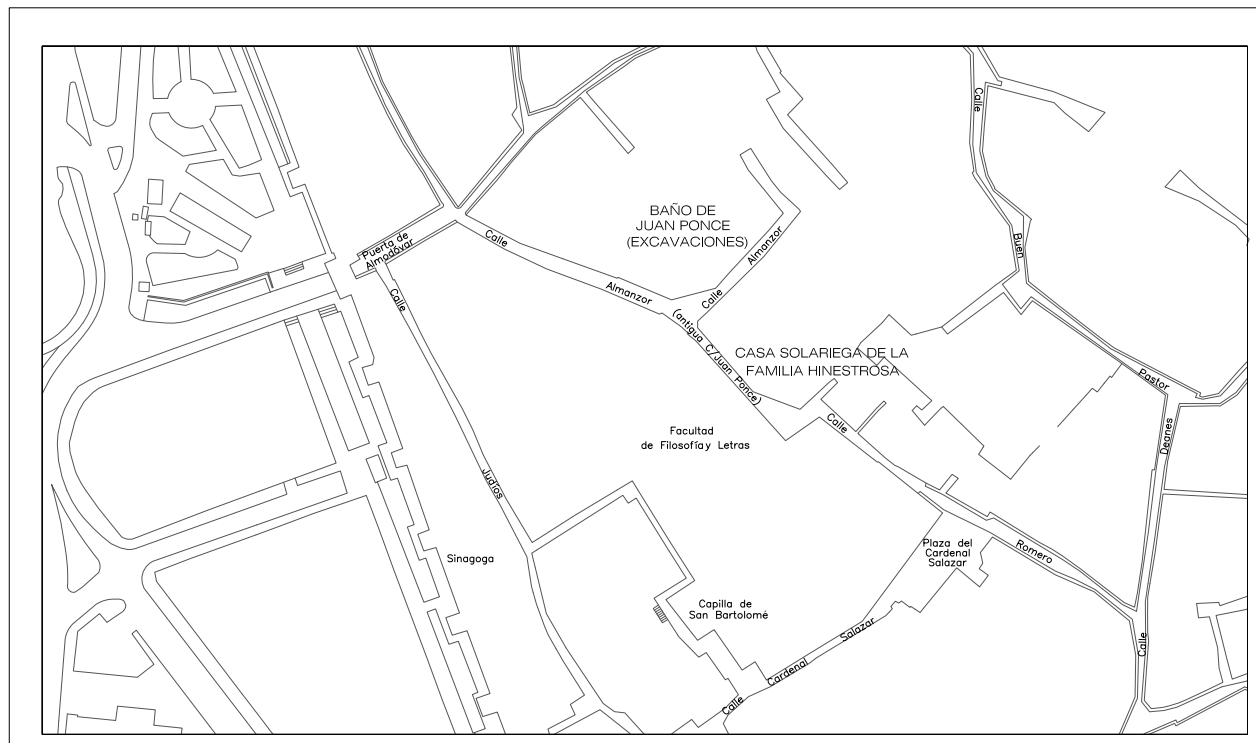

Plano $n^{\circ} 1$. Posible localización del baño de Juan Ponce.

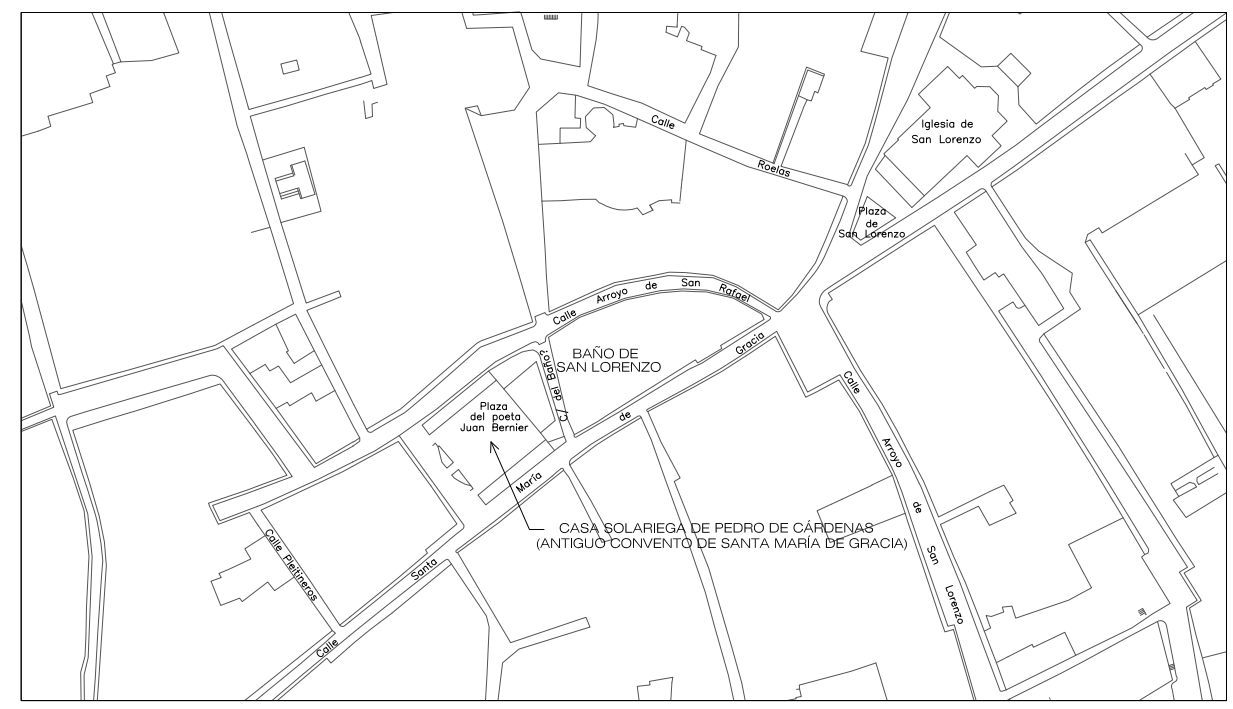

Plano $n^{\circ} 2$. Posible localización del baño de San Lorenzo.

는 $\quad 50 \quad 100 \mathrm{~m} \quad$ Fuente: cartografía vectorial actual de Córdoba

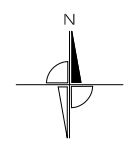




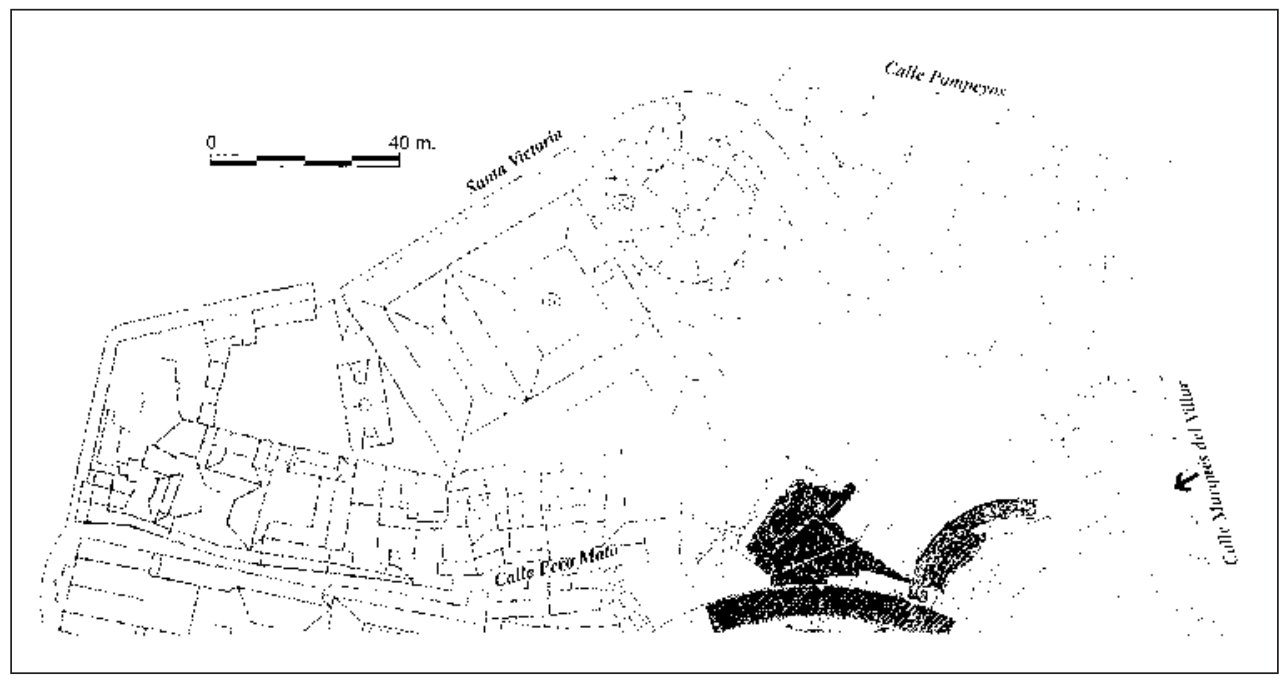

Plano n $n^{0} 3$. Colegio de Santa Victoria (antigua casa de los señores de Santa Eufernia) y su entorno.

(Fuente: plano sacado de Ángel Ventura, "Los edilicios de espectáculos", Córdoba en tiempos de Séneca, Desiderio Vaquerizo (edt.), Córdoba, 1996. p. 83). 